\title{
New guidelines for diagnosis of rheumatic fever; do they apply to all populations?
}

\author{
Pakinam Abdel Aty Marzouk ${ }^{1 \oplus}$, Hala Hamza ${ }^{1 \oplus}$, Naglaa Mosaad $^{1}$, Soha Emam ${ }^{1 \oplus}$, \\ Aya M. Fattouh ${ }^{1 \oplus}$, Lamiaa Hamid ${ }^{2}$ \\ ${ }^{1}$ Department of Pediatric Cardiology, Cairo University Children Hospitals, Faculty of Medicine, Cairo, Egypt; ${ }^{2}$ Department of Critical \\ Care, Faculty of Medicine, Cairo University, Cairo, Egypt.
}

\begin{abstract}
Background and objectives. To evaluate the efficacy of recently updated Jones criteria for diagnosis of rheumatic fever in high incidence populations like Egypt.

Methods. Clinical data of 891 Egyptian patients with rheumatic fever, aged 5-15 years in a highly specialized rheumatic fever clinic were reviewed retrospectively from March 2014 to March 2016. Discriminant analysis was used to detect the most effective predictors for diagnosis of rheumatic fever in our patients incorporating echocardiographic criteria. We compared our results to the most recent update by the American Heart Association.

Results. The most effective predictors of rheumatic fever included arthritis, carditis, chorea, aortic regurgitation, grades of mitral regurgitation $\geq 10 \mathrm{~mm}$ length and velocity $\geq 2.5 \mathrm{~m} / \mathrm{s}$, thick anterior mitral valve leaflets, elevated acute phase reactants, positive family history and prolonged PR interval. Our predictors showed a high sensitivity of $93 \%$, a specificity of $62 \%$ and an overall prediction accuracy of $81.4 \%$.

Conclusion. We concluded that strict application of updated Jones criteria may lead to under diagnosis of rheumatic fever in highly endemic countries. We recommend further studies to examine the sensitivity of the most recent update of Jones criteria on other highly endemic populations.
\end{abstract}

Key words: rheumatic fever, Egypt, subclinical carditis, limiting arthralgia, prediction model.

Egypt has a high prevalence of rheumatic fever; seen in $5.1^{1,2}$ per 1,000 school children. Prompt diagnosis of acute rheumatic fever is important for initiating treatment. ${ }^{2,3}$ Jones Criteria were defined by Dr. T.D. Jones to diagnose acute rheumatic fever ${ }^{4}$ and have been periodically updated. The 1992 update was the most widely used. ${ }^{5}$ Modifications aimed at improving specificity were conducted, however at the expense of sensitivity; hence it has not been sensitive enough to pick up disease in high incidence populations., 5 The World Health Organization developed criteria for the diagnosis of primary and

$凶$ Pakinam Abdel Aty Marzouk

pakinamaty@gmail.com

Received 15th April 2019, revised 3rd August 2019, accepted 10th August 2019. recurrent episodes of rheumatic fever and based on this modified Jones also introduced minimal echocardiographic criteria diagnosing pathological regurgitation, however subclinical carditis hasn't yet been included in Jones criteria. ${ }^{7}$ The Australian guidelines modified criteria for diagnosis of acute rheumatic fever and proposed additional criteria for high-risk groups $^{8,9}$ The Australian guidelines applied the World Health Federation criteria for diagnosing rheumatic heart disease by echocardiography. ${ }^{10}$ Furthermore, the American Heart Association introduced an updated revision of Jones criteria to meet current advances. ${ }^{11}$ In this study we reviewed the criteria for diagnosis of acute rheumatic fever in our patients. We compared our results with the most recent update by the American Heart Association ${ }^{11}$ to emphasize the application of this update on our Egyptian 
children aiming at improving the diagnosis of rheumatic fever and avoiding the impending burden of rheumatic heart disease as a result of under diagnosis of this serious disease in highly endemic areas like Egypt.

\section{Material and Methods}

This is a retrospective study of 5-15 year-old Egyptian patients diagnosed with rheumatic fever, from March 2014 to March 2016. Children were enrolled if they didn't have comorbidities that may affect the heart, joints or brain. We adhered strictly to the updated Jones criteria (positive two major or one major and two minor manifestations plus evidence of recent streptococcal infection). Proven rheumatic fever patients completely fulfilled these criteria while probable rheumatic fever patients were short by either one major or one minor manifestation. We aimed to examine and emphasize the significance of addition of the new diagnostic criteria of rheumatic fever described in the recent guidelines on our children especially subclinical carditis. Also to observe the echocardiographic diagnostic criteria for pathological regurgitation in proved rheumatic fever Egyptian patients and to compare our results with both World Health Organization and World Health Federation criteria.

A data collection sheet was filled, including history taking, Baseline examination and related laboratory investigations. Screening for positive Jones criteria and new debatable criteria namely aseptic monoarthritis, limiting polyarthralgia, and subclinical carditis were done. Aseptic monoarthritis refers to swelling, redness and hotness involving one big joint with limitation of movement, elevated acute phase reactants and dramatic improvement on salicylates treatment.

Limiting polyarthralgia refers to limiting and/or fleeting arthralgia without signs of inflammation (no swelling, redness nor hotness) involving big joints with elevated acute phase reactants and dramatic improvement on salicylates treatment.
Echocardiography was performed for detection of valvular dysfunction ${ }^{7,9,10}$ and rheumatic morphological changes. ${ }^{10}$ Trivial regurgitation was classified according to jet length into jets $<10 \mathrm{~mm}, \geq 10 \mathrm{~mm}$ and $\geq 20 \mathrm{~mm}$ and according to jet velocity into jets $<2.5 \mathrm{~m} / \mathrm{sec}, \geq 2.5 \mathrm{~m} / \mathrm{sec}$ and $>3 \mathrm{~m} / \mathrm{sec}^{7,9,10}$ Regurgitant lengths more than trivial were divided into mild, moderate and severe. Mild regurgitation has a small jet, with a vena contracta width $\sim 3 \mathrm{~mm}$, moderate regurgitation has an intermediate jet with a vena contracta width 3-6.9 mm while a severe mitral regurgitation has a large jet with vena contracta width $\geq 7 \mathrm{~mm}$. The continuous wave signal of the jet is faint or incomplete in case of mild regurgitation, dense in moderate and denser in severe regurgitation. The more severe the aortic regurgitation, the less the pressure half time (500 ms in mild reaching $200 \mathrm{~ms}$ in severe) with diastolic flow reversal in descending aorta in severe aortic regurgitation. ${ }^{12-14}$

Subclinical carditis refers to significant regurgitation of mitral or aortic valve $(\geq 10 \mathrm{~mm}$ in length and $\geq 2.5 \mathrm{~m} / \mathrm{sec}$ velocity) \pm rheumatic valve morphological changes despite the absence of any auscultated murmur. ${ }^{7}$

The research was reviewed and approved by an institutional review board and participation involved informed consent. The study was approved on 12th of November 2017 by Cairo University Committee and reviewed and approved on $30^{\text {th }}$ of January 2018 by the Scientific Committee in Cairo University Children Hospitals and finally approved by Faculty of Medicine, Cairo University Committee on 25th of February 2018; Report number: 164367.

\section{Statistical methods}

All data were gathered, statistically analyzed and tabulated. The presence of individual signs and symptoms were compared between proven and probable rheumatic fever using chi-square tests for binomial variables which were presented as numbers and percentages. Continuous variables were assessed using t-test analysis and were presented as mean \pm standard deviation. 
The statistically significant clinical variables ( $\mathrm{p}$ value $\leq 0.05$ ) were used as independent predictors of proven rheumatic fever utilizing discriminant analysis technique. This multivariate statistical method derives a prediction equation as a linear combination of the independent variables that will discriminate best between groups in the dependent variable (proven and probable rheumatic fever). Functions at group centroid indicate the average discriminant score for subjects in the two groups. Patients are located in the prediction equation according to their discriminant score (unstandardized canonical discriminant coefficients) then diagnosed as probable or proven rheumatic fever accordingly. Stepwise techniques were next done to detect the best predictors of rheumatic fever. Eigen value, canonical correlation, Wilks' lambda, $\mathrm{p}$ value, sensitivity and specificity were calculated for the whole model. The bigger the Eigen value and the smaller the Wilks' lambda, the stronger the discriminating power between proved and probable rheumatic fever.

We used receiver operating characteristic (ROC) curves and area under ROC curve (AUC) to visually and statistically assess sensitivity, specificity and overall performance of our prediction model. Statistical analyses were performed on SPSS 21 statistical software (Statistical Package for Social Science).

\section{Results}

A total of 891 children aged 5-15 years were diagnosed with rheumatic fever during the period of study, $53.4 \%$ (476) were females, with a mean age of $9 \pm 2.5$ years; $62.5 \%$ (557) were diagnosed as proven rheumatic fever while $37.5 \%$ (334) were diagnosed as probable rheumatic fever. The most common presentations were, arthritis followed by subclinical carditis and carditis (Table I). The most common associations between major criteria in our patients were between arthritis and carditis (14.6\%), followed by arthritis and subclinical carditis (11.4\%), carditis and limiting arthralgia (5.8\%), subclinical carditis and chorea $(3.1 \%)$ and carditis and chorea (2.9\%). Four patients had carditis and subcutaneous nodules, two patients had arthritis and erythema marginatum, only one patient had arthritis and subcutaneous nodules.

Echocardiographic study of our patients detected mitral regurgitation in 509 patients.

Table I. Clinical features of the study group.

\begin{tabular}{lcccc}
\hline Features & $\begin{array}{c}\text { Total } \\
(\mathrm{N}=891)\end{array}$ & $\begin{array}{c}\text { Proven RF } \\
(\mathrm{N}=557)\end{array}$ & $\begin{array}{c}\text { Probable RF } \\
(\mathrm{N}=334)\end{array}$ & $\begin{array}{c}\text { P value } \\
\text { Arthritis }\end{array}$ \\
Carditis & $232(59.7 \%)$ & $398(71.5 \%)$ & $134(40.1 \%)$ & $0.0001^{*}$ \\
Chorea & $64(7.2 \%)$ & $247(44.3 \%)$ & $24(7.2 \%)$ & $0.0001^{*}$ \\
Subcutaneous nodules & $4(0.4 \%)$ & $4(0.70 \%)$ & $0(0 \%)$ & $0.0001^{*}$ \\
Erythema marginatum & $3(0.3 \%)$ & $2(0.36 \%)$ & $0(0 \%)$ & 0.06 \\
Subclinical carditis & $299(33.6 \%)$ & $114(20.5 \%)$ & $185(55.4 \%)$ & 0.684 \\
Limited arthralgia & $170(19.1 \%)$ & $64(20.5 \%)$ & $106(31.7 \%)$ & $0.0001^{*}$ \\
Fever & $441(49.5 \%)$ & $317(56.9 \%)$ & $124(37.1 \%)$ & $0.0001^{*}$ \\
Arthralgia & $343(38.5 \%)$ & $201(36.1 \%)$ & $142(42.5 \%)$ & $0.0001^{*}$ \\
Prolonged PR interval & $18(2 \%)$ & $18(3.2 \%)$ & $0(0 \%)$ & $0.033^{*}$ \\
Elevated ESR, CRP & $346(38.8 \%)$ & $269(48.3 \%)$ & $77(23.0 \%)$ & $0.0001^{*}$ \\
Elevated ASO & $395(44.3 \%)$ & $270(48.5 \%)$ & $125(37.4 \%)$ & $0.0001^{*}$ \\
Positive family history & $163(18.3 \%)$ & $86(15.4 \%)$ & $77(23.0 \%)$ & $0.0001^{*}$ \\
\hline
\end{tabular}

*: p value $<0.05$

ASO: antistreptolysin-O, CRP: C-reactive protein, ESR: erythrocyte sedimentation rate, RF: rheumatic fever. 
Table II. Grades of mitral regurgitation in patients with mitral regurgitation.

\begin{tabular}{lccc}
\hline $\begin{array}{l}\text { Grades of mitral } \\
\text { regurgitation }\end{array}$ & $\begin{array}{c}\text { Total } \\
(\mathrm{N}=509)\end{array}$ & $\begin{array}{c}\text { Proven RF } \\
(\mathrm{N}=325)\end{array}$ & $\begin{array}{c}\text { Probable RF } \\
(\mathrm{N}=184)\end{array}$ \\
\hline Trivial MR: $7-9 \mathrm{~mm}$ & $7(1.4 \%)$ & - & $7(3.8 \%)$ \\
Trivial MR: $10-20 \mathrm{~mm}$ & $263(51.7 \%)$ & $116(35.7 \%)$ & $147(79.9 \%)$ \\
Mild MR $\geq 20 \mathrm{~mm}$ & $32(6.3 \%)$ & $15(4.6 \%)$ & $17(9.2 \%)$ \\
Moderate MR & $136(26.7 \%)$ & $124(38.2 \%)$ & $12(6.5 \%)$ \\
Severe MR & $71(13.9 \%)$ & $70(21.5 \%)$ & $1(0.5 \%)$ \\
\hline
\end{tabular}

MR: mitral regurgitation, RF: rheumatic fever.

*The frequency of patients with MR $\geq 10 \mathrm{~mm}$ was higher in proven rheumatic fever $(325 / 325 ; 100 \%)$, compared to probable rheumatic fever $(177 / 184 ; 96 \%$; $p=0.001)$.

Patients are classified into mild, moderate and severe MR according to color flow MR jet, vena contracta width, continuous wave signal of jet and flow convergence zone.

The frequency of patients with grades of mitral regurgitation of jet length $\geq 10 \mathrm{~mm}$ was higher in proven rheumatic fever (325/325; $100 \%$ ), compared to probable rheumatic fever (177/184; 96\%; $p=0.001$, Table II). Rheumatic morphological changes in the mitral valve was detected in $23.9 \%$ (213) of our patients (Fig. 1); of those $39.9 \%$ (85) had one morphological change while $60.1 \%$ (128) had two or more morphological changes. Morphological features included thick mitral valve leaflets, thick subvalvular apparatus, lack of systolic coaptation of mitral valve, restricted posterior mitral valve leaflet, and mitral valve prolapse (Fig. 1). The frequency of two or more morphological changes was in proven rheumatic fever (104/156; 66.7\%), compared to probable rheumatic fever $(24 / 57$; $42.1 \%, \mathrm{p}=0.001)$. Twelve patients had rheumatic mitral valve morphological changes without any functional regurgitation.

Aortic regurgitation was detected in 258 patients. The frequency of patients with grades of aortic regurgitation jet length $\geq 10 \mathrm{~mm}$ was higher in proven rheumatic fever (203/204; $99.5 \%)$, compared to probable rheumatic fever (49/54; 90.7\%, $p=0.001$, Table III). Thick aortic cusps were detected in 3.9\% (35) of our patients;

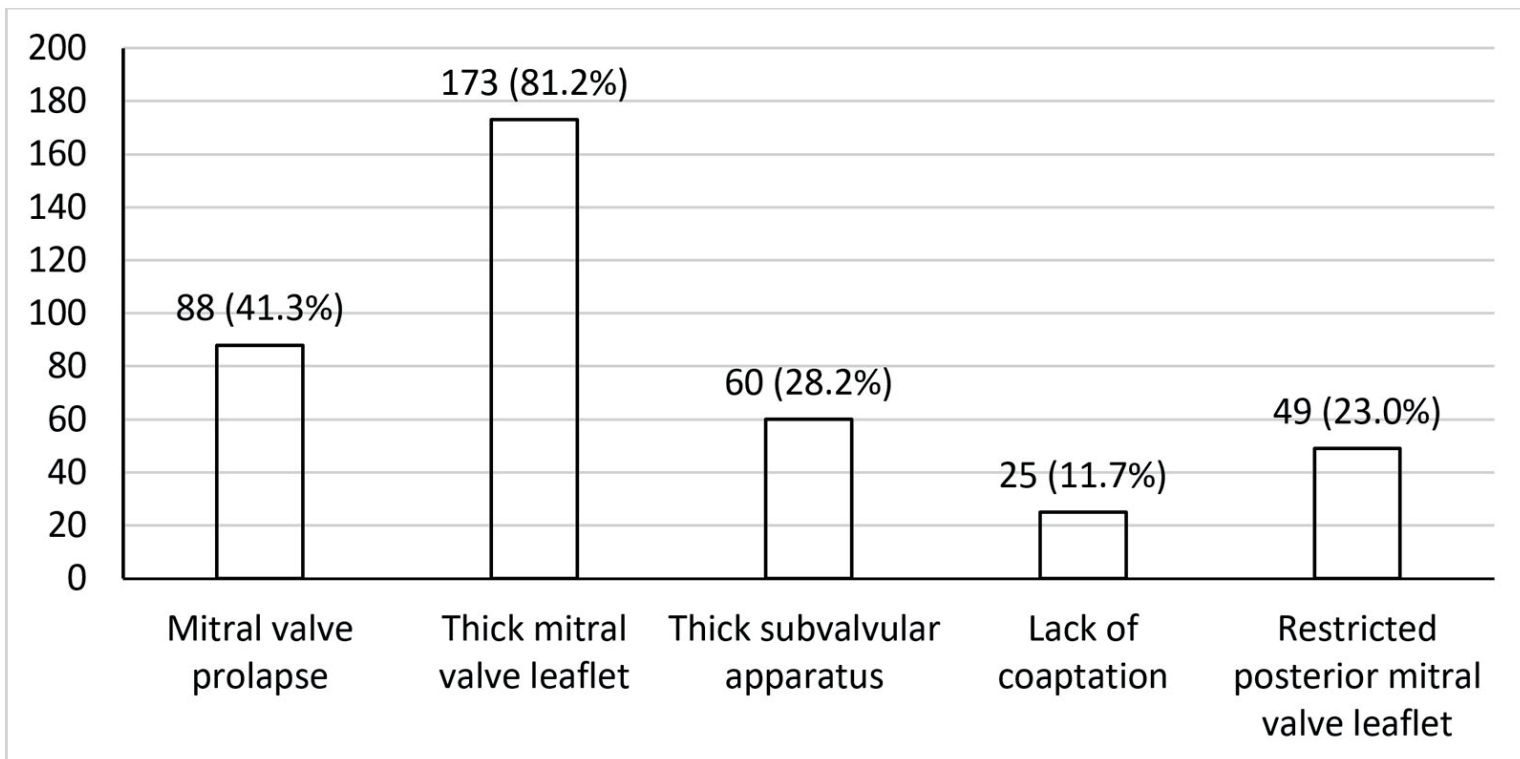

Fig. 1. Distribution of rheumatic morphological changes involving mitral valve; morphological changes were detected in 213 patients. 
Table III. Grades of aortic regurgitation in patients with aortic regurgitation.

\begin{tabular}{lccc}
\hline Grades of aortic regurgitation & $\begin{array}{c}\text { Total } \\
(\mathrm{N}=258)\end{array}$ & $\begin{array}{c}\text { Proven RF } \\
(\mathrm{N}=204)\end{array}$ & $\begin{array}{c}\text { Probable RF } \\
(\mathrm{N}=54)\end{array}$ \\
\hline Trivial AR (7-9 mm length) & $6(2.3 \%)$ & $1(0.5 \%)$ & $5(9.3 \%)$ \\
Trivial AR (10-20 mm length) & $119(45.9 \%)$ & $79(38.7 \%)$ & $40(74.1 \%)$ \\
Mild AR ( >20 mm length) & $52(20.1 \%)$ & $48(23.5 \%)$ & $4(7.4 \%)$ \\
Moderate AR & $57(22.0 \%)$ & $51(25 \%)$ & $6(11.1 \%)$ \\
Severe AR & $25(9.7 \%)$ & $25(12.3 \%)$ & $0(0 \%)$
\end{tabular}

AR: aortic regurgitation, RF: rheumatic fever.

*The frequency of patients with $A R \geq 10 \mathrm{~mm}$ was higher in proven rheumatic fever (203/204; $99.5 \%)$, compared to probable rheumatic fever $(49 / 54 ; 90.7 \%$; $p=0.001)$.

Patients are classified mild, moderate and severe AR according to color flow AR jet width, vena contracta width, continuous wave signal of jet, pressure half time, and diastolic flow reversal.

$4.7 \%(26 / 557)$ in proven rheumatic fever and $2.7 \%(9 / 334)$ in probable rheumatic fever with $(p=0.097)$. Thick aortic cusps were detected in six patients without any functional aortic regurgitation. Double valve affection (mitral and aortic regurgitation) was detected in $24 \%$ (214) of our patients.

In our patients, $33.6 \%$ (299) had subclinical carditis; $38.1 \%$ (114) had proven rheumatic fever while $61.9 \%$ (185) had probable rheumatic fever $(\mathrm{p}=0.0001)$. In patients with subclinical carditis, $42.8 \%$ (128) had associated other rheumatic fever major criteria where $34.4 \%$ had arthritis, $33.4 \%$ had limiting polyarthralgia, $9.4 \%$ had chorea and $0.6 \%$ had erythema marginatum.
Trivial mitral regurgitation (jet length 10-20 mm) was detected in $29.5 \%$ (263) of patients, $44 \%$ (116) had proven rheumatic fever ( $p=0.0001)$. In patients with trivial mitral regurgitation (jet length $10-20 \mathrm{~mm}), 31.6 \%$ (83) had associated arthritis; $80.2 \%$ had proven rheumatic fever $(\mathrm{p}=$ $0.0001) ; 9.5 \%$ (25) had associated chorea, and all had proven rheumatic fever $(\mathrm{p}=0.0001)$.

Trivial aortic regurgitation (jet length 10$20 \mathrm{~mm}$ ) was detected in $13.4 \%$ (119) of our patients; $66.4 \%$ (79) had proven rheumatic fever $(\mathrm{p}=0.0001)$. In patients with trivial aortic regurgitation (jet length 10-20 mm), 41.2\% (49) had associated arthritis; $93.9 \%$ of these patients had proven rheumatic fever $(\mathrm{p}=0.0001) ; 10.9 \%$

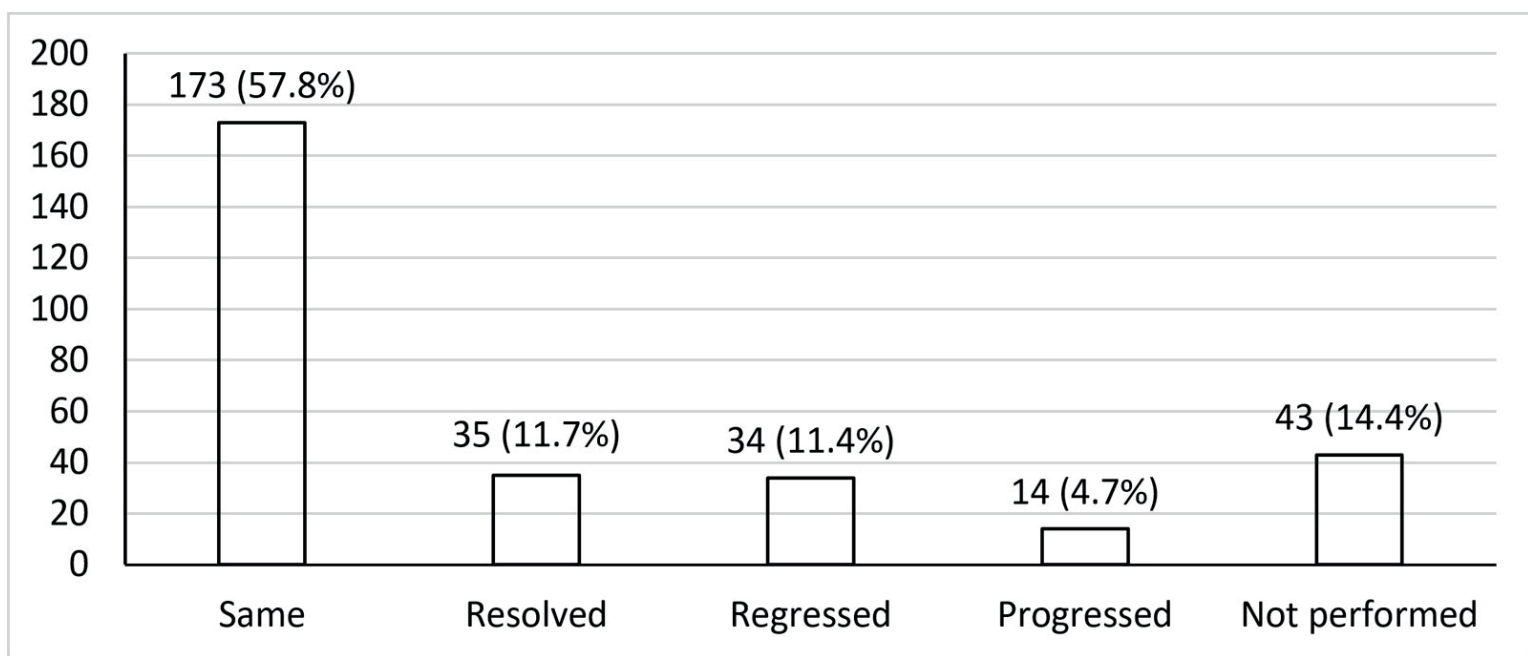

Fig. 2. Echocardiographic follow-up in patients with subclinical carditis; Follow-up echocardiography was scheduled after 1-year for 299 patients with subclinical carditis. In two patients, mitral regurgitation became clinically auscultated. 
(13) had associated chorea, and all had proven rheumatic fever $(p=0.003)$.

Follow up echocardiography was scheduled after 1 year for all patients with subclinical carditis (Fig. 2). The follow up was missed in only $14.4 \%$ (n: 43 ) of them and in two patients, mitral regurgitation became clinically auscultated. All patients showed good compliance to secondary prophylaxis of long acting penicillin, except five patients who showed persistent lesions by follow up.

We used discriminant analysis to detect the most effective predictors of rheumatic fever in our children where significant variables by univariate analysis ( $p$ value $\leq 0.05$ ) have been used as independent predictors for diagnosis of rheumatic fever to construct the prediction model (Table IV). The final prediction model after step wise approach included 9 variables: arthritis, carditis, chorea, aortic regurgitation, grades of mitral regurgitation $\geq 10 \mathrm{~mm}$ length \& velocity $\geq 2.5 \mathrm{~m} / \mathrm{s}$, thick anterior mitral valve leaflets, elevated erythrocyte sedimentation rate and C- reactive protein, positive family history, and prolonged PR interval (Table V). The final prediction model had an Eigen value 0.783, canonical correlation 0.663 , Wilks' lambda 0.561 , p value 0.0001 , sensitivity $93 \%$ and specificity $62 \%$ with overall prediction accuracy of $81.4 \%$.

ROC curve of final model was done with AUC 0.889 (Fig. 3).

Discriminant analysis was also used to detect the best echocardiographic predictors of proven rheumatic fever where significant echocardiographic criteria by univariate analysis $(p \leq 0.05)$ have been used as independent predictors for diagnosis of rheumatic fever to construct echocardiographic criteria prediction model (Table VI). The final echocardiographic prediction model after stepwise approach included 4 variables namely: grades of mitral regurgitation $\geq 10 \mathrm{~mm}$ length \& velocity $\geq 2.5$ $\mathrm{m} / \mathrm{s}$, grades of aortic regurgitation $\geq 10 \mathrm{~mm}$ length \& velocity $\geq 2.5 \mathrm{~m} / \mathrm{s}, \geq 2$ rheumatic mitral morphological changes, thick mitral valve leaflets. The final echocardiographic criteria prediction model had an Eigen value 0.1 , canonical correlation 0.301, Wilks' lambda 0.909 , and $\mathrm{p}$ value 0.0001 . The model had a sensitivity of $98.6 \%$, specificity $7.2 \%$ and an overall prediction accuracy of $64.3 \%$ as it correctly classified 549 out of 557 patients with proven rheumatic fever, 24 out of 334 patients with probable rheumatic fever however, 310 patients were recommended to be classified as proven rheumatic fever by our model though being diagnosed as probable rheumatic fever according to the updated Jones criteria.

\section{Discussion}

Our study showed a predominance of females with rheumatic fever (53.4\%) this was similar to other studies. ${ }^{15,16}$ In contrast to a study where rheumatic fever was more in males $(62.5 \%) .{ }^{17}$ Age of our patients (5-15 years) was similar to other studies. ${ }^{18}$ However rheumatic fever in ages $<5$ years or $>15$ years has been reported by some studies. ${ }^{19,20}$

Similar to what have been reported by other studies, ${ }^{21,22}$ arthritis, carditis and chorea were the most common major manifestations encountered in our patients. Mitral regurgitation was the most common valvular lesion followed by aortic regurgitation which is similar to other studies. ${ }^{23}$ Although mitral stenosis is uncommon before 10 years of age, ${ }^{24} 1.7 \%$ of our patients had mitral stenosis and $1.5 \%$ had both mitral regurgitation and stenosis. However, aortic stenosis wasn't detected in our patients which adds to the evidence that rheumatic heart disease is an uncommon cause of aortic stenosis. $^{25}$

Several studies, as in ours, have documented the prevalence of subclinical carditis and its association with other major criteria. ${ }^{26-29}$ Most of these studies, as in our study, used World Health Organization criteria in diagnosing a pathological regurgitation. ${ }^{26,29-37}$ 
Table IV. The performance of predictors in the diagnosis of rheumatic fever.

\begin{tabular}{lccccc}
\hline Predictors of rheumatic fever & $\begin{array}{c}\text { Standardized canonical } \\
\text { discriminant function } \\
\text { coefficients }\end{array}$ & P-value & $\begin{array}{c}\text { Sensitivity } \\
(\%)\end{array}$ & $\begin{array}{c}\text { Specificity } \\
(\%)\end{array}$ & AUC \\
\hline Arthritis & 0.672 & 0.0001 & 74.8 & 55.7 & 0.657 \\
Carditis & 0.434 & 0.0001 & 91.1 & 49.8 & 0.684 \\
Chorea & 0.495 & 0.0001 & 93.8 & 40 & 0.549 \\
Subclinical carditis & -0.175 & 0.0001 & 38.1 & 25.2 & 0.462 \\
Limiting arthralgia & -0.172 & 0.0001 & 37.6 & 31.6 & 0.465 \\
Elevated ESR, CRP & 0.264 & 0.0001 & 77.7 & 47.2 & 0.626 \\
Fever & 0.090 & 0.0001 & 71.9 & 46.7 & 0.599 \\
Arthralgia & 0.136 & 0.033 & 58.6 & 35.0 & 0.468 \\
Positive family history & -0.092 & 0.003 & 52.8 & 35.3 & 0.554 \\
Prolonged PR interval & 0.098 & 0.0001 & 100 & 38.3 & 0.516 \\
Elevated ASO & 0.078 & 0.0001 & 68.4 & 42.1 & 0.555 \\
Mitral regurgitation & 0.091 & 0.022 & 59.0 & 33.5 & 0.540 \\
Aortic regurgitation & 0.193 & 0.0001 & 79.1 & 44.2 & 0.602 \\
Grades of MR $\geq 10$ mm length \& $\geq 2.5$ & 0.175 & 0.0001 & 64.7 & 40.3 & 0.606 \\
$\quad$ m/s velocity & & & & & \\
Grades of AR $\geq 10 m m$ length \& $\geq 2.5$ & -0.076 & 0.0001 & 80.2 & 44.5 & 0.615 \\
$\quad$ m/s velocity & & & & & \\
Rheumatic morphological features of & -0.183 & 0.001 & 81.6 & 40.6 & 0.561 \\
$\quad$ mitral valve $\geq 2$ & & & & & \\
Mitral stenosis & 0.040 & 0.006 & 100 & 38.1 & 0.513 \\
Thick MV leaflets & 0.294 & 0.0001 & 81.5 & 42.1 & 0.579 \\
Thick subvalvular apparatus & 0.047 & 0.013 & 78.3 & 38.6 & 0.513 \\
Lack of systolic coaptation & 0.042 & 0.0001 & 100 & 38.6 & 0.522 \\
Restricted PMVL & 0.016 & 0.003 & 81.6 & 38.6 & 0.512 \\
\hline AR a & & & & &
\end{tabular}

AR: aortic regurgitation, ASO: antistreptolysin-O, AUC: area under the curve, CRP: C-reactive protein, ESR: erythrocyte sedimentation rate, MR: mitral regurgitation, MV: mitral valve, PMVL: posterior mitral valve leaflets.

*The standardized canonical discriminant coefficients can be used to rank the importance of each variable in the prediction model. A high standardized discriminant function coefficient means that the groups differ a lot on that variable.

A meta-analysis was done to study the prevalence and outcome of subclinical carditis in acute rheumatic fever including more than 1700 rheumatic fever cases in studies done during 1996 through March 2005. ${ }^{38}$ Of 63 articles, 23 articles only documented the prevalence of subclinical carditis in their study population. ${ }^{38}$ World Health Organization criteria were used completely in 12 studies and incompletely in five studies; the remaining six studies did not specify criteria used. $^{38}$ In this meta-analysis, age range of patients was similar to our study. ${ }^{38}$ The prevalence of subclinical carditis ranged from $0 \%$ in one study ${ }^{39}$ to $53 \%$ in 23 studies. $^{38}$
The weighted pooled prevalence of subclinical carditis in acute rheumatic fever in this metaanalysis was $16.8 \%$. Eleven studies only attempted to follow-up their patients. ${ }^{38}$ Follow up revealed progressive valve dysfunction in some studies ${ }^{29,40,41}$ improvement and even resolution in other studies. ${ }^{37,42,43}$ Others found new cases of subclinical carditis, mostly diagnosed within the first year of followup. ${ }^{44}$ One study reported recurrent subclinical carditis after 4 years of initial resolution. ${ }^{28}$ The weighted pooled prevalence of persistence or deterioration (3-23 months) after acute rheumatic fever diagnosis was $44.7 \%$. Of 
Table V. Final prediction model of rheumatic fever.

\begin{tabular}{lcc}
\hline Best predictors of rheumatic fever & $\begin{array}{c}\text { Standardized canonical discriminant } \\
\text { function coefficients }\end{array}$ & AUC \\
\hline Arthritis & 0.621 & 0.657 \\
Carditis & 0.435 & 0.684 \\
Chorea & 0.314 & 0.549 \\
Aortic regurgitation & 0.196 & 0.602 \\
Grades of MR $\geq 10$ mm length \& velocity $\geq 2.5 \mathrm{~m} / \mathrm{s}$ & 0.177 & 0.606 \\
Elevated ESR, CRP & 0.273 & 0.626 \\
Prolonged PR interval & -0.117 & 0.516 \\
Thick mitral valve leaflets & 0.293 & 0.579 \\
Positive family history & -0.425 & 0.554
\end{tabular}

AUC: area under the curve, CRP: C-reactive protein, ESR: erythrocyte sedimentation rate, MR: mitral regurgitation.

*The standardized canonical discriminant coefficients can be used to rank the importance of each variable in the prediction model. A high standardized discriminant function coefficient means that the groups differ a lot on that variable.

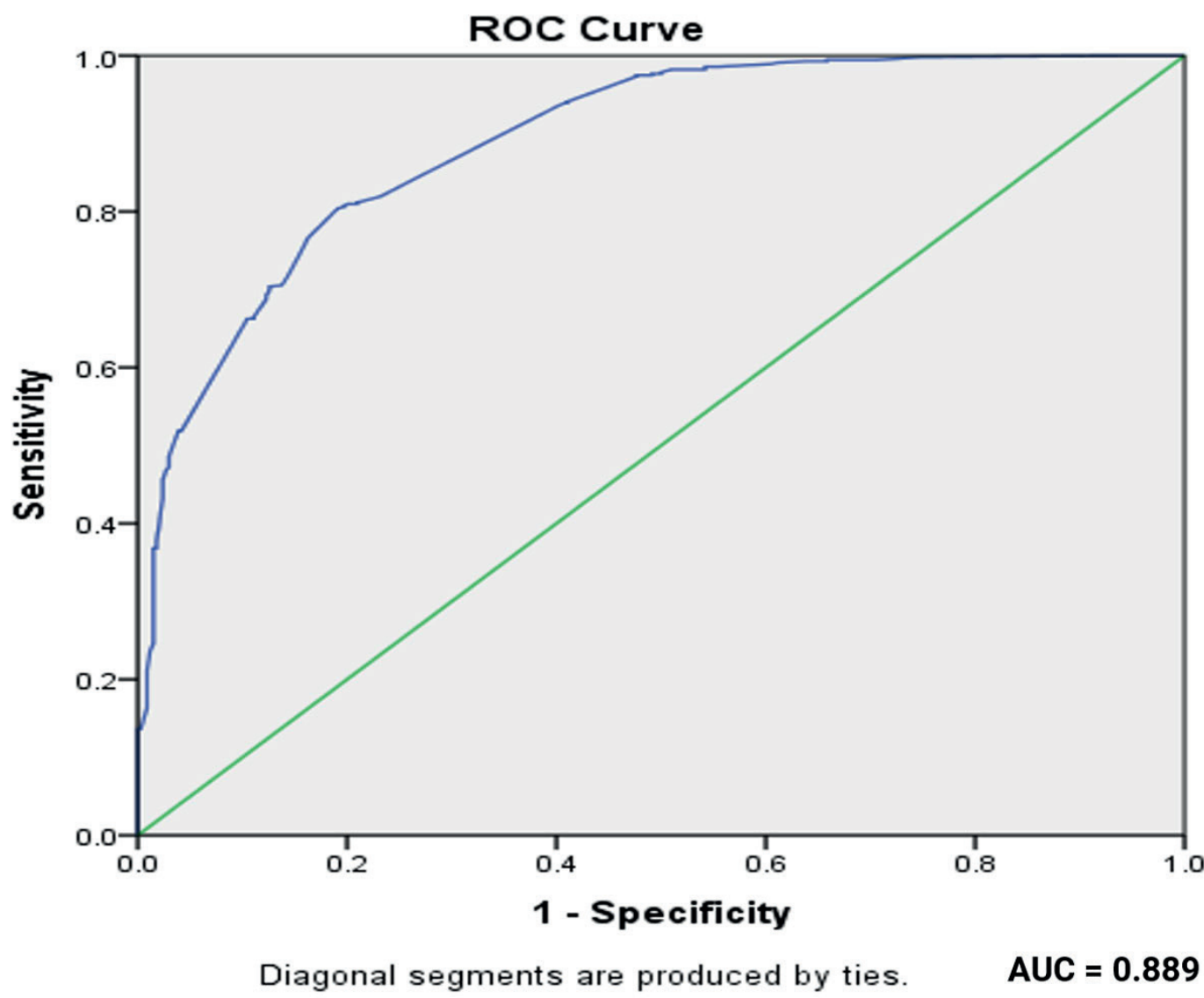

Fig. 3. Receiver operating characteristic (ROC)* curve of rheumatic fever prediction model. ROC curves were done to visually and statistically assess the sensitivity, specificity, and overall performance of predictors of proved rheumatic fever. The area under the ROC curve of the whole prediction model was significantly high: 0.889 .

${ }^{*}$ ROC curve, is a graphical plot of the sensitivity vs. (1 - specificity) for a binary classifier system as its discrimination threshold is varied. The area under the ROC curve (AUC) corresponds to the probability that a physician using the prediction model will correctly classify a pair of patients with and without disease. 
Table VI. The contribution of significant echocardiographic criteria in the prediction model.

Significant echocardiographic criteria Standardized canonical discriminant function coefficients

Grades of mitral regurgitation $\geq 10 \mathrm{~mm}$ length \& velocity $\geq 2.5 \mathrm{~m} / \mathrm{s}$ 0.330

Grades of aortic regurgitation $\geq 10 \mathrm{~mm}$ length \& velocity $\geq 2.5 \mathrm{~m} / \mathrm{s}$

0.544

Rheumatic mitral morphological changes (2 or more)

Mitral stenosis

Mitral valve prolapse

0.148

Thick mitral valve leaflets

0.803

Thick subvalvular apparatus

Lack of systolic coaptation

Restricted posterior mitral valve leaflets

0.142

The standardized canonical discriminant coefficients can be used to rank the importance of each variable in the prediction model. A high standardized discriminant function coefficient means that the groups (proven and probable rheumatic fever) differ a lot on that variable.

patients followed for ( $>23$ months), two thirds had persistence and one third had resolution. ${ }^{38}$

The number of patients followed up in these studies was very small. ${ }^{38}$ Unlike our study, most studies didn't detail which patients received secondary prophylaxis and few studies reported whether valvular regurgitation remained subclinical or became clinical at any stage. ${ }^{38}$ The predictors of improvement, persistence or deterioration of subclinical carditis were unknown. However, this improvement or deterioration emphasizes the significance of early diagnosis, early prescription of secondary prophylaxis and close follow up for patients with subclinical carditis.

Vijaya's echocardiographic criteria were evolved using the common echocardiographic features detected in 492 patients with isolated manifestations of acute rheumatic fever such as arthritis or chorea ${ }^{45}$ and its efficacy in an Indian population was tested in a prospective double blinded study including 333 patients and showed sensitivity of $81 \%$ and specificity of $93 \%{ }^{32}$ This study also used World Health Organization criteria but unless valvular regurgitation was associated with rheumatic morphological features with an echo score of $\geq 6$, it was not taken as pathological. Vijaya's echocardiographic criteria avoided over diagnosis, however, morphological changes are often minimal in acute carditis, so we believe that if patients with isolated pathological regurgitation were not considered rheumatic or even probable rheumatic fever, many patients would be missed.

Our study strongly agrees with the recommendations of World Health Federation, Australian guidelines and the new American Heart Association updated revision of Jones Criteria $^{9-11}$ that subclinical carditis should be added as a major criterion in the diagnosis of rheumatic fever in high risk populations like Egypt. The set of morphological changes that indicate the diagnosis of rheumatic heart disease as well as the recommended two echocardiographic categories by World Health Federation were strongly applicable on our patients. On the other hand, we still believe that we should rely upon the World Health Organization criteria ${ }^{7}$ in diagnosing a pathological regurgitation. Trivial pansystolic, mosaic mitral regurgitation of jet length 10$20 \mathrm{~mm}$ and velocity $\geq 2.5 \mathrm{~m} / \mathrm{sec}$ should not be taken lightly nor considered physiological as stated by World Health Federation, Australian guidelines and approved later by American Heart Association. ${ }^{9-11}$ This was very much proven by our study.

In our patients, $19.1 \%$ (170) had limiting polyarthralgia; $58.8 \%$ of them had associated 
subclinical carditis, $30.6 \%$ had carditis, while $8.2 \%$ had chorea. If limiting polyarthralgia was taken lightly many patients with subclinical carditis would not have been diagnosed. Similarly, in an Indian study $70 \%$ of their patients had polyarthralgia; subclinical carditis was detected in $46.9 \%$ of them. ${ }^{45}$ We believe that limiting, fleeting polyarthralgia involving big joints that was associated with elevated erythrocyte sedimentation rate and showed dramatic response to salicylates should be added as a major criterion in the diagnosis of rheumatic fever especially in high risk populations as recommended by Australian guidelines and American Heart Association ${ }^{8,9,11}$ however we suggest that non limiting, non-fleeting polyarthralgia should still be considered a minor criterion as it didn't show a high significance for diagnosis of rheumatic fever in our patients.

In 127 patients with acute rheumatic fever presentation, 7 patients (5.5\%) had monoarthritis; two patients had arthritis in one knee while five patients had arthritis in one ankle. Five patients had associated carditis, two had subclinical carditis, three had mitral regurgitation, while four patients had aortic regurgitation. Elevated erythrocyte sedimentation rate, C-reactive protein and antistreptolysin $\mathrm{O}$ titer were reported in all 7 patients. Monoarthritis resolved dramatically after a trial of salicylate treatment in all 7 patients. Our study emphasizes the significance of monoarthritis as stated by many studies ${ }^{31,46,47}$ and we also strongly suggest its addition as a major criterion in diagnosis of rheumatic fever especially in high risk populations as stated by Australian guidelines ${ }^{9}$ and American Heart Association. ${ }^{11}$

Erythema marginatum was reported in 3 patients only $(0.3 \%)$, this low incidence was similarly reported by other studies. ${ }^{45,48}$ Two patients had associated carditis, one had subclinical carditis and one had arthritis which indicates that this criterion shouldn't be considered irrelevant as described by other studies. ${ }^{45}$ Besides, low incidence might be due the evanescent nature of these lesions, so it could be missed even by expert clinicians especially in dark-skinned patients.

The incidence of subcutaneous nodules in our patients was very low too; reported in 4 patients only $(0.4 \%)$. One patient had associated arthritis, one patient had chorea and all four patients had severe carditis with a $p$ value 0.002 . Subcutaneous nodules were more frequently reported in patients with severe carditis by many other studies too. ${ }^{5,45}$

Our study as well as many other studies pointed to the importance of positive family history reported in $18.3 \%$ of our patients with a $p$ value 0.003 in diagnosis of rheumatic fever. We believe, as proven by other researches, that genetic susceptibility factors among patients with acute rheumatic fever might point to a totally new set of diagnostic tools. $3,49,50$

We concluded that echocardiography should be performed in all patients with suspected rheumatic fever and subclinical carditis should be considered a diagnostic major criterion. We recommend adopting World Health Organization criteria when diagnosing a pathological regurgitation. Regurgitation or stenosis should definitely be considered rheumatic by echocardiography if associated with rheumatic morphological features. Patients with isolated rheumatic morphological changes or with isolated pathological regurgitation or stenosis should be diagnosed probable rheumatic fever. Limiting, fleeting polyarthralgia and aseptic monoarthritis showing dramatic response to salicylates should be considered as diagnostic major criteria in high risk populations. Positive family history showed a high significance in diagnosis of our rheumatic fever patients so future genetic studies are mandatory. Highly suspicious patients despite not fulfilling Jones criteria should be diagnosed probable rheumatic fever, prescribed long acting penicillin and followed up yearly to revise diagnosis. We compared our results to the most recent update by the 
American Heart Association. We concluded that strict application of updated Jones criteria may lead to under diagnosis of rheumatic fever in highly endemic countries. We recommend further studies to examine the sensitivity of the most recent update of Jones criteria on other highly endemic populations.

Unfortunately, there is no single laboratory test that definitely establishes the diagnosis of acute rheumatic fever which makes the diagnosis difficult and mainly based on clinical criteria. We adhered strictly to the updated jones criteria in diagnosis of proven rheumatic fever patients. However highly suspicious patients despite not completely fulfilling the criteria were diagnosed as probable rheumatic fever, prescribed secondary prophylaxis and followed up yearly for possible change of diagnosis.

Retrospective studies are known to carry risk of inconsistent methodology; however, we were following a standard protocol which minimized any possible risk of bias.

We only conducted 1 follow up echocardiographic study after 1 year for patients with subclinical carditis and $14.4 \%$ missed their follow up despite being contacted. A prospective long-term follow up is needed in the future to demonstrate its potential significance.

\section{Acknowledgments}

We gratefully acknowledge the work of the study staff at Cairo University Children Hospitals together with the study echocardiographers and clinicians at the rheumatic fever clinic, Centre of Social and Preventive Medicine for their help in this study.

\section{REFERENCES}

1. Abdel-Moula AM, Sherif AA, Sallam SA, Mandil AM, Kassem AS, Zaher SR. Prevalence of rheumatic heart disease among school children in Alexandria, Egypt: a prospective epidemiological study. J Egypt Public Health Assoc 1998; 73: 233-254.
2. Carapetis JR. Rheumatic heart disease in developing countries. N Engl J Med 2007; 357: 439-441.

3. Bryant PA, Robins-Browne R, Carapetis JR, Curtis N. Some of the people, some of the time: susceptibility to acute rheumatic fever. Circulation 2009; 119: 742753.

4. Jones TD. The diagnosis of rheumatic fever. JAMA 1944; 126: 481-484.

5. Guidelines for the Diagnosis of Rheumatic Fever. Jones Criteria 1992 Update. Special Writing Group of the Committee on Rheumatic fever, Endocarditis and Kawasaki Disease of the Council on Cardiovascular Disease in the Young of the American Heart Association. JAMA 1992; 268: 2069-2073.

6. Ferrieri $\mathrm{P}$, for the Jones Criteria Working Group. Proceedings of the Jones Criteria Workshop. Circulation 2002; 106: 2521-2523.

7. WHO Study Group. Rheumatic Fever and Rheumatic Heart Disease: Report of a WHO Expert Consultation; 20 October-1 November 2001, Geneva, Switzerland. Technical Report Series No. 923. Geneva: World Health Organization, 2004.

8. Carapetis J, Brown A, Walsh $\mathrm{W}$, et al; National Heart Foundation of Australia (RF/RHD Guidelines Development Working Group) and the Cardiac Society of Australia and New Zealand. Diagnosis and management of acute rheumatic fever and rheumatic heart disease in Australian - An evidencebased review. 2006.

9. RHD Australia (ARF/RHD Writing Group), National Heart Foundation of Australia, Cardiac Society of Australia and New Zealand. The Australian Guideline for Prevention, Diagnosis, and Management of Acute Rheumatic Fever and Rheumatic Heart Disease (2nd ed). Casuarina, Australia: RHD Australia; 2012.

10. Remenyi B, Wilson N, Steer A, et al. World Heart Federation criteria for echocardiographic diagnosis of rheumatic heart disease - an evidence - based guideline. Nat Rev Cardiol 2012; 9: 297-309.

11. Gewitz MH, Baltimore RS, Tani LY, et al; American Heart Association Committee on Rheumatic Fever, Endocarditis, and Kawasaki Disease of the Council on Cardiovascular Disease in the Young. Revision of the Jones criteria for the diagnosis of acute rheumatic fever in the era of Doppler Echocardiography: a Scientific Statement from the American Heart Association. Circulation 2015; 131: 1806-1818.

12. Lancellotti P, Moura L, Picrard LA, et al; European Association of Echocardiography. European Association of Echocardiography recommendations for the assessment of valvular regurgitation. Part 2: mitral and tricuspid regurgitation (native valve disease). Eur J Echocardiogr 2010; 11: 307-332. 
13. Zoghbi WA, Enriquez-Sarano M, Foster E, et al; A report from the American Society of Echocardiography's Nomenclature and Standards Committee and Task Force on Valvular Regurgitation. Recommendations for evaluation of the severity of native valvular regurgitation with two-dimensional and Doppler echocardiography. J Am Soc Echocardiogr 2003; 16: 777-802.

14. Lancelotti P, Tribouilloy C, Hagendorff A, et al; European Association of Echocardiography recommendations for the assessment of valvular regurgitation. Part I: aortic and pulmonary regurgitation (native valve disease) Eur J Echocardiogr 2010; 11 : 223-244.

15. Melka A. Rheumatic heart disease in Gondar College of Medical Sciences Teaching Hospital: Socio-demographic and clinical profile. Ethiop Med J 1996; 34: 207-216.

16. Bhardwaj R, Kandoria A, Marwah R, et al. Prevalence of rheumatic fever and rheumatic heart disease in rural population of Himachal- a population based study. J Assoc Physicians India 2012; 60: 13-14.

17. Sabri M, Kadivar MR. Correlation between the severity of carditis and the level of acute phase reactants and anti-streptolysin $\mathrm{O}$ titre in acute rheumatic fever. A retrospective study in Shiraz. Med J Islam Repub Iran 1999; 13: 11-14.

18. Carapetis JR, Wolff DR, Currie BJ. Acute rheumatic fever and rheumatic heart disease in the top end of Australia's northern territory. Med J Aust 1996; 164: 146-149.

19. Tani LY, Veasy LG, Minich LL, Shaddy RE. Rheumatic fever in children younger than 5 years: is the presentation different? Pediatrics 2003; 112: 1065-1068.

20. Kumar V, Abbas AK, Fausto N, Mitchell RN. Robbins Basic Pathology (8th ed). Philadelphia: Saunders Elsevier, 2007: 403-406.

21. Miyake CY, Gauvreau K, Tani LY, Sundel RP, Newburger JW. Characteristics of children discharged from hospitals in the United States in 2000 with the diagnosis of acute rheumatic fever. Pediatrics 2007; 120: 503-508.

22. Olgunturk R, Canter B, Tunaoglu FS, Kula S. Review of 609 patients with acute rheumatic fever in terms of revised and updated Jones criteria. Int J Cardiol 2006; 112: 91-98.

23. Chockalingam A, Gnanavelu G, Elangovan S, Chockalingam V. Clinical spectrum of chronic rheumatic heart disease in India. J Heart Valve Dis 2003; 12 : 577-581.

24. Chandrashekhar Y, Westaby S, Narula J. Mitral stenosis. Lancet 2009; 374: 1271-1283.
25. Alkhalifa MS, Ibrahim SA, Osman SH. Pattern and severity of rheumatic valvular lesions in children in Khartoum, Sudan. East Mediterr Health J 2008; 14: 1015-1021.

26. Beg A, Sadiq M. Subclinical valvulitis in children with acute rheumatic fever. Pediatr Cardiol 2008; 29: 619-623.

27. Caldas AM, Terreri MTR, Moises VA, et al. What is the true frequency of carditis in acute rheumatic fever? A prospective clinical and Doppler blind study of 56 children with up to 60 months of follow up evaluation. Pediatr Cardiol 2008; 29: 1048-1053.

28. Figueroa FE, Fernandez MS, Valdes $P$, et al. Prospective comparison of clinical and echocardiographic diagnosis of rheumatic carditis: long term follow-up of patients with subclinical disease. Heart 2001; 85: 407-410.

29. Lanna CCD, Tonelli E, Barros MVL, Goulart EMA, Mota CCC. Subclinical rheumatic valvulitis: a longterm follow-up. Cardiol Young 2003; 13: 431-438.

30. Ozdemir O, Isik S, Abaci A, ve ark. Akut romatizmal ateşte sessiz düşman: subklinik kardit. Türk Kardiyoloji Derneği Arşivi 2011; 39: 41-46.

31. Cann MP, Sive AA, Norton RE, McBride WJH, Ketheesan N. Clinical presentation of rheumatic fever in an endemic area. Arch Dis Child 2010; 95: 455-457.

32. Vijayalakshmi IB, Vishnuprabhu RO, Chitra N, Rajasri R, Anuradha TV. The efficacy of echocardiographic criterions for the diagnosis of carditis in acute rheumatic fever. Cardiol Young 2008; 18: 586-592.

33. Caldas AM, Terreri MTRA, Moises VA, Silva CMC, Carvalho AC, Hilário MOE. The case for utilizing more strict quantitative Doppler echocardiographic criterions for diagnosis of subclinical rheumatic carditis. Cardiol Young 2007; 17: 42-47.

34. Rayamajhi A, Sharma D, Shakya U. Clinical, laboratory and echocardiographic profile of acute rheumatic fever in Nepali children. Ann Trop Paediatr 2007; 27: 169-177.

35. Ozer S, Hallioğlu O, Ozkutlu S, Celiker A, Alehan D, Karagöz T. Childhood acute rheumatic fever in Ankara, Turkey. Turk J Pediatr 2005; 47: 120-124.

36. Khriesat I, Najada A, Al-Hakim F, Abu-Haweleh A. Acute rheumatic fever in Jordanian children. East Mediterr Health J 2003; 9: 981-987.

37. Ozkutlu S, Hallioglu O, Ayabakan C. Evaluation of subclinical valvar disease in patients with rheumatic fever. Cardiol Young 2003; 13: 495-499.

38. Turbridy-Clark M, Carapetis JR. Subclinical carditis in rheumatic fever: a systematic review. Int J Cardiol 2007; 119: 54-58. 
39. Vasan RS, Shrivastava S, Vijayakumar M, Narang R, Lister BC, Narula J. Echocardiographic evaluation of patients with acute rheumatic fever and rheumatic carditis. Circulation 1996; 94: 73-82.

40. Abernethy M, Bass N, Sharpe N, et al. Doppler echocardiography and the early diagnosis of carditis in acute rheumatic fever. Aust N Z J Med 1994; 24: 530-535.

41. Hilario MO, Andrade JL, Gasparian AB, Carvalho AC, Andrade CT, Len CA. The value of echocardiography in the diagnosis and follow up of rheumatic carditis in children and adolescents: a 2 year prospective study. J Rheumatol 2000; 27: 10821086.

42. Ralph A, Jacups S, McGough K, McDonald M, Currie $\mathrm{BJ}$. The challenge of acute rheumatic fever diagnosis in a high-incidence population: a prospective study and proposed Guidelines for Diagnosis in Australia's Northern Territory. Heart Lung Circ 2006; 15: 113118.

43. Folger Jr GM, Hajar R, Robida A, Hajar HA. Occurrence of valvular heart disease in acute rheumatic fever without evident carditis: colour flow Doppler identification. Br Heart J 1992; 67: 434438.

44. Panamonta M, Chaikitpinyo A, Kaplan EL, Pantongwiriyakul A, Tassniyom S, Sutra S. The relationship of carditis to the initial attack of Sydenham's chorea. Int J Cardiol 2004; 94: 241-248.
45. Vijayalakshmi IB, Mithravinda J, Deva ANP. The role of echocardiography in diagnosing carditis in the setting of acute rheumatic fever. Cardiol Young 2005; 15: 583-588.

46. Parks T, Kado J, Colquhoun S, Carapetis J, Steer A. Under diagnosis of acute rheumatic fever in primary care settings in a developing country..Trop Med Int Health 2009; 14: 1407-1413. Erratum in: Trop Med Int Health 2010; 15: 384.

47. Carapetis JR, Currie BJ. Rheumatic fever in a high incidence population: the importance of monoarthritis and low grade fever. Arch Dis Child 2001; 85: 223-227.

48. Al-Eissa YA. Acute rheumatic fever during childhood in Saudi Arabia. Ann Trop Pediatr 1991; 11: 225-231.

49. Guilherme L, Köhler KF, Postol E, Kalil J. Genes, autoimmunity and pathogenesis of rheumatic heart disease. Ann Pediatr Cardiol 2011; 4: 13-21.

50. Engel ME, Stander R, Vogel J, Adeyemo AA, Mayosi $\mathrm{BM}$. Genetic susceptibility to acute rheumatic fever: a systematic review and meta-analysis of twin studies. PLoS One 2011; 6: e25326. 